\title{
A Study on Chronic Subdural Haematoma Observed in Neurosurgery, Especially in Elderly Patients
}

\author{
${ }^{1}$ Dr.Tofael Hossain Bhuiyan ${ }^{2}$ Dr. Md. Emdadul Hoque ${ }^{3}$ Dr. Monirul Islam \\ ${ }^{1}$ Associate Professor, Dept. Of Neurosurgery, Rangpur Medical College Hospital, Bangladesh \\ 2 \\ Assistant Professor, Dept. Of Neurology, Rangpur Medical College Hospital, Bangladesh \\ ${ }^{3}$ Assistant Professor, Dept. Of Neurosurgery, Faridpur Medical College, Bangladesh
}

\begin{abstract}
:
Chronic subdural haematoma is predominantly a disease of the elderly. The general aim of the study was to evaluate the effect of management of CSDH after burrhole evacuation with or without subgaleal drainage.

Grouping of study population were divided into 2 groups such as: Group-A (Control): The first case and every alternative cases which were operated with drain and Group-B (Case): The second case and every alternative cases which were operated without drain. 70 cases of CSDHs haematoma were identified in different age groups. They were diagnosed by no-contrast CT scan of head. All patients were followed until discharged from the hospital. The age ranges of both groups were from 10 to 90 years and mean age $58.71 \%$ and $56.14 \%$. Male predominate in both groups. The most aetiology of CSDHs in both groups was head trauma. Common presenting symptoms of both groups were headache and contra lateral limb weakness. 70 patients from both group under went on surgical intervention are leading a good quality of life according to GCS, GOS, and Markwalder scale. Operative morbidity in group A have $18.18 \%$ (wound infection and neurological deterioration) and in group B was $2.9 \%$ (only neurological deterioration). Operative mortality in group A was $5.70 \%$ (death) and in group B was $2.9 \%$ (Death). Most of the death disability occurs either due to the complication of frailty or poor morbidity. The recommendation of the study was management of CSDH through burrhole evacuation without subgaleal drainage should be the method of treatment.
\end{abstract}

Keywords: Chronic subdural haematoma, Elderly, Subgaleal,Drainage, Markwalder scale, Evacuation

\section{Introduction}

In neurosurgery it is observed that Chronic subdural haematoma is one of the most common problemsin usually elderly patients. Especially elderly patients are often frail and malnourished and the goal of evacuating the haematoma thus often conflicts with the goal of minimizing anaesthetic and surgical risks. Various approaches involving simple burr hole drainage with or without subsequently performing closed system drainage have been used, with variable results. After surgery the main problem is the intra cranial accumulation of air, which causes compression of the brain or rehaemorrhages.

Chronic Subdural haematoma generally occur in the elderly, with the average age being 63 yrs. Head trauma is identified in $<50 \%$ (some times rather trivial trauma). Other risk factors for Chronic subdural haematoma are alcohol abuse, seigures, CSF shunts, Coagulopathies ( including therapeutic anticoagulent) and patients with risk for falls (eg with hemiplegia from previous CVA ). CSDHs are bilateral in 20 to $25 \%$ of cases. Haematoma Thickness tends to be larger in older patients due to decrease in the brain weight and increase in subdural space with age CSDHs classically contains dark (motoroil ) 'fluid' which does not clot. SDH that develop from 3 days to 3 weeks after head injury are called subacute and those that 'appear' later than 3 weeks after injury are called chronic.

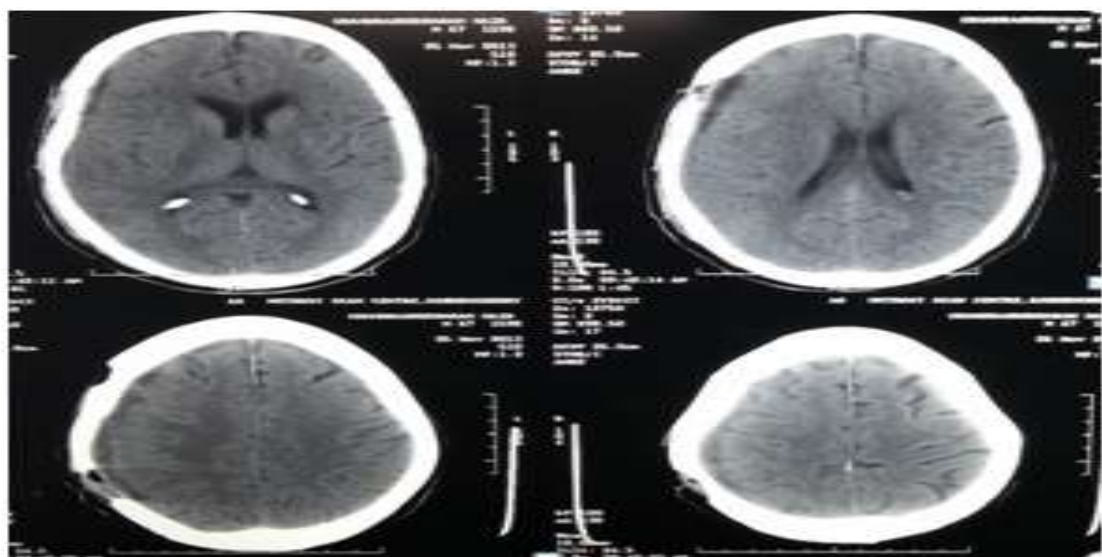

Figure 1: Postoperative CT showing complete resolution. 
Patient with Chronic subdural haematoma reaches the neurosurgical centers when they are symptomatic and progressively deteriorating causing poor outcome. In this context this prospective study was done to find out the outcome of CSDHs managed surgically with or without drain to prevent recurrence and other complications and make a guide line for treatment for patients having CSDHs.Above discussions and literature of different authors shows mortality and morbidity due to chronic subdural haematoma is significantly high and needs attention of neurosurgeons to improve the condition.

\section{Objective}

The general aim of the study is:

- To evaluate the effect of management of CSDH after burrhole Evacuation with or without subgaleal drainage

The specific objectives are:

- To assess the outcome of the management of CSDH with or without subgaleal drain after burr hole evacuation.

- To assess the morbidity and mortality of CSDH followings surgical management after burr hole evacuation with or without subgaleal drainage.

- To assess the efficancy of drainage system in the management of CSDH after burr hole evacuation with or without subgaleal drainage

- To evaluate the recovery of the patients CSDH after burr hole evacuation with or without subgaleal drainage.

$\bullet$

\section{Methodology}

Table-1:Study type, place of study and duration

\begin{tabular}{|l|l|l|}
\hline Study type: & Place of study & Duration of study \\
\hline Randomized control clinical trial & $\begin{array}{l}\text { Department of Neurosurgery, } \\
\text { Dhaka Medical College Hospital. }\end{array}$ & 2 (Two) years \\
\hline
\end{tabular}

\section{Inclusion criteria:}

Table-2:CSDHs diagnosed clinically and Radiologically

\begin{tabular}{|c|c|}
\hline a) Clinically & b) Radiologically \\
\hline $\begin{array}{ll}\text { - } & \text { Headache } \\
\text { - } & \text { Behavior disturbance } \\
\text { - } & \text { Vomiting } \\
\text { - } & \text { Contra lateral limb } \\
\text { - } & \text { weakness } \\
\text { - } & \text { Vertigo disorder } \\
\text { - } & \text { Seizure }\end{array}$ & $\begin{array}{l}\text { - Non Contrast CT scan of head showing } \\
\text { Chronic subdural haematoma } \\
\text { - CT findings }\end{array}$ \\
\hline
\end{tabular}

There is a hypodense/isodense/mixdense are located just under the dura. (Nons-contrast film) with evidence of midline shifting.

\section{Exclusion criteria for surgically managed cases:}

- Patients with use of anti-thrombolytic and anti-coagulant drugs.

- Age $<12$ years.

\section{Sampling Techniques:}

Purposive sampling techniques were applied for the study. All patients admitted in the Neurosurgery department, Dhaka Medical College Hospital who were diagnosed as CSDHs in non-Contrast CT scan of Head.

\section{Grouping of study population:}

Divided into 2 groups:

- Group-A (Control): The first case and every alternative cases which were operated with drain.

- Group-B (Case): The second case and every alternative cases which were operated without drain.

\section{Ethical Consideration:}

The aims and objectives of the study along with its procedure, diagnostic methods, risks and benefits for this study where explained to the patient's relatives or attendants of the patients in easily understandable local language and 
then informed consent was taken for each confidential and the procedure would be helpful for both attending neurosurgeons and subsequent management which was approved by ethical committee.

\section{Sample Size:}

The patients admitted in the department of Neurosurgery, Dhaka Medical College Hospital, Dhaka, during the study period. Total 70 patients were included in these studies which were divided into two groups. 35 patients were in each group. They were diagnosed as CSDHs by non-contrast CT scan of head. The patients were excluded by exclusion criteria as mentioned earlier.

Group-A (Control): The first case and every alternative cases which were operated with drain.

Group-B (Cases): The second cases and every alternative cases which were operated without drain.

\section{Measurement of outcome variables:}

Are discussed and considered on basis of

\section{A. Demographic and clinical variables:}

- Age of the patients

- Sex of the patients

- Glasgow coma scale (GCS) at presentation.

B. Imaging Variables: (CT scan relatedvariables)

- Side and site of haematoma

- Shifting of midline.

C. Surgical Management variables:

- Subgaleal drainage palaced or not placed.

D. Surgical outcome variable:

- Glasgow, coma scale (GCS)(Freeman, E.A.1987)

Glasgow outcome scale (GOS) score: - In this study the term early surgical outcome is used to designate the outcome on the day of discharge usually the $3^{\text {rd }}$ POD.

Score-5: Good recovery resumption of normal life despite minor deficit ("return to work" not reliable).

Score-4: Moderate disabled (disabled but independent) - Travel by public transport, can in sheltered setting (exceeds mere ability to perform "activity of daily living").

Score-3: Severe disability (conscious but disabled) - Dependent for daily support.

Score-2: Persistent vegetative state - Unresponsive and speechless. May open eyes and wake cycles.

Score-1: Death.(Jennett,B.Bond,M,1975)

- The Markwalder scale of Chronic subdural haematoma :

Grade 0: Patient neurologically normal

Grade 1: Patient alert and orientated ; absence of mild symptoms such as headache, or mild neurological deficit such as reflex asymmetry

Grade 2: Patient drowsy or disorientated, or variable neurological dificit such as hemiparesis

Grade 3: Patient stuporous but responding appropriately to noxious stimuli; sever focal sings such as hemiplegia

Grade 4: Patient comatose with absent motor responses painful stimuli; Decerebrate or decorticate posturing (Ernestus 1997)

Data collection procedure:

1) At admission, a detailed history of the illness was taken from the patients attendants. The researcher himself carried out through general and neurological examinations. GCS score and Markwalder score were determined and recorded.

2) Findings of CT scan were recorder.

3) Operative findings were noted and recorded in the data sheet.

\section{Data analysis procedure:}

The following steps analyzed collected data,

- Collected data was collected and edited manually. Then the collected data was entered into SPSS (Statistical Package for Social Science) computer software programme, (13.5)

- The entered data was checked and verified.

- The same programme analyzed data.

- Data was presented in tabular form.

- Statistical calculations were performed by SPSS computer programme . 


\section{Results}

Some of the important study results are shown in tabulated form below:

The age ranged from 18 to 90 years. Mean age in group A is $58.71 \%$ and in group B is $56.14 \%$. Total mean is $57.43 \%$. The age distribution of 70 patients in group A and group B shown Table-1.

Table-3:Age distribution in group A and in group B. $(\mathrm{n}=70)$

\begin{tabular}{|l|lll|}
\hline \multirow{2}{*}{ Age (Year) } & \multicolumn{2}{|c|}{ Group } & Total \\
\cline { 2 - 3 } & $\begin{array}{l}\text { Group A (n=35) } \\
(\mathrm{n}=35)\end{array}$ & \multicolumn{1}{c|}{ Group B } & \\
\hline $15-30$ & $4(11.4) \#$ & $2(5.7)$ & $6(8.6)$ \\
$35-45$ & $4(11.4)$ & $7(20.0)$ & $11(18.0)$ \\
$46-60$ & $8(22.9)$ & $10(28.6)$ & $18(25.7)$ \\
$61-75$ & $12(34.3)$ & $13(37.1)$ & $25(35.7)$ \\
$76-90$ & $7(20.0)$ & $3(8.6)$ & $10(14.3)$ \\
\hline Total & $35(100.0)$ & $35(100.0)$ & $70(100.0)$ \\
\hline Mean age \pm SE & $58.71 \pm 2.95(18-88)$ & $56.14 \pm 2.66(22-92)$ & $57.43 \pm 1.98(18-90)$ \\
(Range) & & & \\
\hline
\end{tabular}

Out of 70 patients with CSDHs male patients were group A 28 (80.00\%),

Group B $29(82.90 \%)$ and female patients in group A 7 (20.00\%) and group B $6(17.1 \%)$

Table-4:Sex distribution in group A and group B. $(\mathrm{n}=70)$

\begin{tabular}{|l|cl|c|}
\hline \multirow{2}{*}{ Sex } & \multicolumn{2}{|c|}{ Group } & \multirow{2}{*}{ Total } \\
\cline { 2 - 3 } & Group A (n=35) & Group B (n=35) & \\
\hline Male & $28(80.0) \#$ & $29(82.9)$ & $57(81.4)$ \\
Female & $7(20.0)$ & $6(17.1)$ & $13(18.8)$ \\
\hline Total & $35(100.0)$ & $35(100.0)$ & $70(100.0)$ \\
\hline
\end{tabular}

Male were mostly affected in both groups.Out of 70 patients with CSDHs, most of the patients where in grade 0 in both groups.

Table-5: $1^{\text {st }}$ Prospective day grading of CSDHs in group A and group B according to Markwalder scale. $(\mathrm{n}=70)$

\begin{tabular}{|l|c|cc|}
\hline \multirow{1}{*}{ GOS } & \multicolumn{2}{|c|}{ Group } & \multicolumn{2}{c|}{ Total } \\
\cline { 2 - 3 } & $\begin{array}{c}\text { Group A (n=35) } \\
\text { Group B (n=35) }\end{array}$ & $26(74.3)$ & $50(71.4)$ \\
\hline Grade 0 & $24(68.6) \#$ & $7(20.0)$ & $13(18.6)$ \\
Grade 1 & $6(17.1)$ & $1(2.9)$ & $4(5.7)$ \\
Grade 2 & $3(8.6)$ & $1(2.9)$ & $3(4.3)$ \\
Grade 3 & $2(5.7)$ & $35(100.0)$ & 70 \\
\hline Total & $35(100.0)$ & & \\
$(100.0)$ & & & \\
\hline
\end{tabular}

Chi square value $=1.49, \mathrm{DF}=3, \mathrm{p}$ value $=0.685$

Table-6:Shows post operative complication in group A and in group B. (n=67) among 70 patients Out of 70 patients with CSDHs, in group A Death 2 (5.7\%) and group B Death 1(2.9\%)

\begin{tabular}{|l|cr|c|}
\hline \multirow{2}{*}{ Complications } & \multicolumn{2}{|c|}{ Group } & Total \\
\cline { 2 - 3 } & Group A (n=35) & Group B (n=35) & \\
\hline $\begin{array}{l}\text { Complication } \\
\text { (10.44) }\end{array}$ & $6(22.9)$ & $1(2.95)$ & 7 \\
$\begin{array}{l}\text { No complication } \\
(86.56)\end{array}$ & $27(77.1)$ & $33(97.05)$ & 60 \\
\hline $\begin{array}{l}\text { Total } \\
(100.0)\end{array}$ & $33(100.0)$ & $34(100.0)$ & 67 \\
\hline
\end{tabular}

Chi square value $=3.72, \mathrm{DF}=1, \mathrm{p}$ value $=0.05$ (after Yates correction) 
Table-7: Showing condition of (both Groups) patients with CSDHs in relation to Glasgow outcome scale. $(\mathrm{n}=70)$

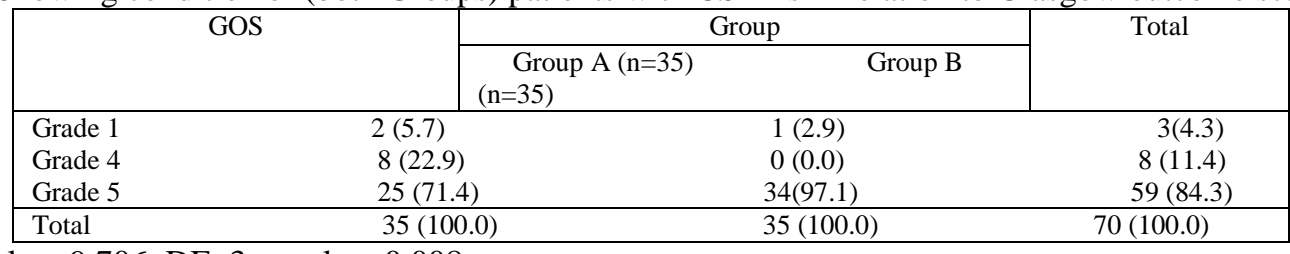

Chi square value $=9.706, \mathrm{DF}=3, \mathrm{p}$ value $=0.008$.

So result of our study is statistically significant.

\section{Discussion}

CSDHs is a neurosurgical emergency which makes the surgeon worried with its malignant behavior. Hi morbidity and mortality of the patients following CSDHs has led to search for better treatment modalities there surgical treatment to improve the prognosis of the patient.In advance world the rapid transportation, emergency medical services and improved imaging facilities CSDHs continue to contribute significantly to better operative outcome.In our country condition is much worse due to ignorance, poverty, lack of advanced transport facilities, poor referral system, lack of good number of neurosurgical center and neurosurgeons especially outside Dhaka city.In managing the patients of CSDHs is a matter of debate. Up to now there have been no prospective randomized studies to determine which surgical approach is most appropriate. As has been shown contemporary treatment options ranges from simple twisted drill to burr hole evacuation to craniotomy without drainage to marsupialization of haematoma membrane. ${ }^{[4]}$

Weir and Gordon noticed the fluid of CSDHs has a high concentration of fibrin degradation product and high plasminogen activator level the vascular outer membrane. These also contribute to further accumulation of CSDH Yeamashima and Yamamoto have found proliferating macrocapillaries in the capsule, besides increase permeability. These also contribute to further accumulation of CSDH. ${ }^{[5]}$

Despite the high incidence of CSDHs to date relatively few authors have under taken a systemic analysis of the result attained following burrhole craniectomy and system drainage. Factors that did not have a significant on their outcome included whether the SDH formation was bilateral or unilateral, the extent of neomembrane organization of the haematoma and the amount of primary cerebral expansion following decompression.. ${ }^{[6]}$

The common occurance of CSDHs in older patient raises some diagnostic and therapeutic difficulties. Despite general agreement about the indication of Operation, the extent of surgery is still controversial. In the management of CSDHs burrhole crainiostomy and closed system drainage should be the method of choice for initial treatment. ${ }^{[7]}$

Clinician try to determined that an extended surgical approaches with partial membranectomy has no advantages regarding the rate of re operation and their outcome. ${ }^{[8]}$

This study carried out in the department of neurosurgery, Dhaka Medical College Hospital, Dhaka. During the period of January 2005 to December 2006, the final study was carried out on 70 patients. In this study, we have selected 70 consecutive patients of CSDH. There 70 patients were grouped into group-A and Group-B. 35 patients were in each group.Group-A: Management of CSDH after burrhole evacuation with subgaleal drain, Group-B: Management of CSDH after burrhole evacuation without subgaleal drain. In this study the age ranged between 18 to 90 years and mean age was in group A $58.71 \%$ an in group B was $56.14 \%$. In the relevant international studies the mean age incidence of CSDHs is 60 years (Beldzinski et al 1997), which correlates with our study.In our study there was male predominance in both group (in group A, male was $80 \%$ and female was $20 \%$, in group B, male was $82.9 \%$ and female was $17.1 \%$ ).In a relevant study male and female was 6:1 (Sambasivan, 1997) which correlates with our study.The leading symptoms in our study were headache and contralateral limb weakness $54.28 \%$ in a relevant study headache and hemiperesis were $53.5 \%$ (Weigel et al 2003) which correlates with our study.History of direct head trauma is frequently encounter risk factor. However, CSDHs may also occur in absence of head trauma. In our series direct head trauma was the most common cause of CSDHs $85.71 \%$, in group A and $82.86 \%$, in group B and remained unclear $14.29 \%$, in group A and $15.71 \%$ in group B. In a relevant study the percentage of CSDHs with a history recent head trauma is $55 \%$ and caused in un-cleared in $20 \%$ (Krupp and Jans 1995) which correlates with our study.The operative morbidity in-group A was $(18.18 \%)$ and in-group B was $2.95 \%$. The operative morbidity in relevant study show $4.2 \%$ and $3.8 \%$ (Krupp and Jans 1995) which correlates with our study. This evidence based review of contemporary surgical techniques for the treatment of CSDHs identified twist drill craniostomy and burrhole craniostomy as the safest methods. Burrhole craniostomy has the best cure to complication ration and is superior to twist drill craniostomy in the treatment of recurrence (Wrigal et al, 2003).

Reported morbidity from CSDHs varies widely. In a relevant study, the immediate mortality (within 4 weeks) was $17 \%$. There were no death from complication of surgery; patient died either direct effect of CSDHs or due to compromised morbidity ${ }^{[9]}$ in our study mortality in group A was $5.70 \%$ and group B was $2.90 \%$ which correlates with the study. In this study highest number of patients were in the active period of life in group A, 71.4\% patient were in GOS 5 and in group B, $97.10 \%$ patients were in GOS 5 category. In relevant study about $90 \%$ of patients were in GOS 5 category (Krupp and Jans, 1995) which correlates with our study. In our study we compared group A with group B relation to GOS during $1^{\text {st }}$ postoperative day using Chi square value $=9.706, D F=3, p$ value $=0.008$. So result of our 
study is statistically significant. In this study according to Markwalder scale most of the patients were in Grade 3 in group A and in group B in preoperative condition. After burrhole evacuation most of the patients were rapidly improved that is $68.60 \%$ in group A, were in Grade 0 and $74.3 \%$ in group B, and were in Grade 0 , in first postoperative period. This result correlates with an international. Study shows that burrhole evacuation without closed system drainage should be the method of choice for the treatment of CSDH. Cranitomy should be reserved for those patients in home the haematoma re-accumulates or residual haematoma membranes prevent re expansion of the brain.

\section{Conclusion}

The present study shows the result of management of CSDHs by surgical intervention e.g. burrhole evacuation with or without subgaleal drainage system In our study we found burrhole evacuation without subgaleal drainage group had complications in postoperative period like wound infection, neurological deterioration, even death were less in group without subgaleal drainage system. According to all outcome variables like GCS, GOS and Markwalder scale showes in group B is a better procedure which was statistically significant. Thus in the management of CSDHs by burrhole evacuation without subgaleal drainage system is a better procedure. Management of CSDH through burrhole evacuation without subgaleal drainage should be the method of treatment.

\section{References}

[1]. TH Aung, WK Wong, HP Mo, CS Tsang, Management of chronic subdural haematoma: burr holedrainage, replacement with Hartmann's solution, andclosed-system drainage, HKMJ, 5(4), 1999; 383-6.

[2]. Mark S Greenberg, Chronic subdural hematoma: hand book of neurosurgery (7th edn), 2010, p. 899-902.

[3]. http://medcraveonline.com/JNSK/JNSK-05-00168.php

[4]. Weigel R, Schmiedek P, Krauss JK. The outcome of contemporary surgery for chronic subdural hematoma: evidence-based review. J Neurol Neurosurg Psychiatry, 74(7), 2003, 937-43.

[5]. Sambasivan M, An overview of chronic subdural hematoma: experience with 2300 cases. Surg Neurol 47,1997, 418-422. doi: 10.1016/S0090-3019(97)80756-2. pmid:9131021

[6]. Krupp WF, Jans PJ: Treatment of chronic subdural hematoma with burr-hole craniostomy and closed drainage. Br J Neuro-surg 1995;9:619-27.

[7]. Ernestus RI, Beldzinski P, Lanfermann H, Klug N. Chronic subdural hematoma: surgical treatment and outcome in 104 patients. Surg Neurol 48(3) 1997,220-25

[8]. Lee JY, Ebel H, Ernestus RI, Klug N. Various surgical treatments of chronic subdural hematoma and outcome in 172 patients: is membranectomy necessary? Surg Neurol, 61(6), 2004; 523-527

[9]. Muhammad Asghar, Vedamurthy Adhiyaman, M W Greenway, Bhimal K Bhowmick, and A Bates, Chronic subdural haematoma in the elderly_a North Wales experience, J R Soc Med. 95(6), 2002, 290-292. 